\title{
A Developmental Gene (Tolloid/BMP-1) Is Regulated in Aplysia Neurons by Treatments that Induce Long-Term Sensitization
}

\author{
Qing-R Liu, ${ }^{1}$ Samer Hattar, ${ }^{1}$ Shogo Endo, ${ }^{1}$ Kathleen MacPhee, ${ }^{1}$ Han Zhang, ${ }^{2}$ Leonard J. Cleary, ${ }^{2}$ \\ John H. Byrne, ${ }^{2}$ and Arnold Eskin ${ }^{1}$ \\ ${ }^{1}$ Department of Biochemical and Biophysical Sciences, University of Houston, Houston, Texas 77204, and ${ }^{2}$ Department \\ of Neurobiology and Anatomy, University of Texas Medical School, Houston, Texas 77225
}

Long-term sensitization training, or procedures that mimic the training, produces long-term facilitation of sensory-motor neuron synapses in Aplysia. The long-term effects of these procedures require mRNA and protein synthesis (Montarolo et al., 1986; Castellucci et al., 1989). Using the techniques of differential display reverse transcription PCR (DDRT-PCR) and ribonuclease protection assays (RPA), we identified a cDNA whose mRNA level was increased significantly in sensory neurons by treatments of isolated pleural-pedal ganglia with serotonin for $1.5 \mathrm{hr}$ or by long-term behavioral training of Aplysia. The effects of serotonin and behavioral training on this mRNA were mimicked by treatments that elevate cAMP. The Aplysia mRNA increased by serotonin and behavioral training was $41-45 \%$ identical to a developmentally regulated gene family which includes Drosophila tolloid and human bone morphogenetic protein-1 (BMP-1). Both tolloid and BMP-1 encode metalloproteases that might activate TGF- $\beta$ (transforming growth factor $\beta$ )-like molecules or process procollagens. Aplysia tolloid/BMP1-like protein (apTBL-1) might regulate the morphology and efficacy of synaptic connections between sensory and motor neurons, which are associated with long-term sensitization.

Key words: Aplysia; tolloid; metalloprotease; sensitization; learning; memory; TGF- $\beta$
Sensitization of defensive withdrawal reflexes in Aplysia is a simple form of nonassociative learning in that the response to a test stimulus is enhanced by a noxious stimulus (Kandel and Schwartz, 1982; Byrne, 1987). Enhancement of the reflex responses is mediated, at least in part, by presynaptic facilitation of the connections between sensory neurons and motor neurons (Castellucci and Kandel, 1976; Walters et al., 1983; Frost et al., 1985; Lee et al., 1995). The long-term form of facilitation, which persists for at least $24 \mathrm{hr}$ after training, is associated with neuronal growth and formation of new synaptic connections between sensory neurons and motor neurons (Bailey and Chen, 1983; Bailey and Kandel, 1993).

Mechanisms responsible for the induction of sensitization include release of serotonin (5-HT) from facilitatory interneurons, elevation of cAMP, and activation of cAMP-inducible genes in sensory neurons (Bernier et al., 1982; Walters et al., 1983; Schacher et al., 1988; Scholz and Byrne, 1988; Glanzman et al., 1989; Dash et al., 1990; Byrne et al., 1993; Clark and Kandel, 1993; Emptage and Carew, 1993). Both RNA and protein synthesis are required for induction of long-term facilitation (Montarolo et al., 1986; Castellucci et al., 1989). At early times (15 min after 5-HT treatment), transcription of Aplysia CCAAT enhancer-binding

\footnotetext{
Received July 8, 1996; revised Oct. 25, 1996; accepted Oct. 29, 1996.

This work was supported by Air Force Office of Naval Research Grant F4962092-J-0494 (A.E.), National Institutes of Health (NIH) Grant NS28462 (A.E.), NIH Grant NS19895 (J.H.B.), National Institute of Mental Health Award K05 MH00649 (J.H.B.), and National Science Foundation Grant IBN 9320549 (L.J.C.). We thank Drs. D. Kuhl and E. Kandel for providing the cDNA clones of HSC70. Aplysia cDNA libraries were generous gifts from Dr. Alexander Kurosky, University of Texas, Medical Branch at Galveston. We thank Ms. Una Ren for help in sequencing apTBL-1 cDNA and Mr. Zhong Chen for assisting with sequence analysis.

The nucleotide sequence of apTBL-1 cDNA has been submitted to GenBank under accession number U57369.

Correspondence should be addressed to Dr. Arnold Eskin, Department of Biochemical and Biophysical Sciences, University of Houston, Houston, TX 77204-5934 Copyright (C) 1997 Society for Neuroscience 0270-6474/97/170755-10\$05.00/0
}

protein (apC/EBP) is increased, presumably due to activation of the cAMP response element binding protein (CREB) (Dash et al., 1990; Kaang et al., 1993; Alberini et al., 1994; Bartsch et al., 1995).

Changes in protein synthesis also occur during training procedures and up to $24 \mathrm{hr}$ after training procedures (Barzilai et al., 1989; Noel et al., 1993). The synthesis of several proteins has been studied using two-dimensional polyacrylamide gel electrophoresis (2D-PAGE), but this approach samples only a limited population of proteins. To identify additional proteins altered during longterm facilitation, we used differential display reverse transcription PCR (DDRT-PCR) to analyze mRNA changes in sensory neurons produced by application of 5-HT. In contrast to 2D-PAGE, DDRT-PCR allows identification of mRNAs of rare and large proteins (Liang and Pardee, 1992; Liang et al., 1993). Ribonuclease protection assays (RPA) were used to confirm changes in the levels of specific mRNAs identified using DDRT-PCR (Lee and Costlow, 1987). Using these techniques, we found an Aplysia gene (apTBL-1) similar to Drosophila tolloid (Shimell et al., 1991) and human bone morphogenetic protein-1 (BMP-1) (Wozney et al., 1988), the mRNA of which was increased in pleural-pedal ganglia treated with 5-HT for $1.5 \mathrm{hr}$. The mRNA of the Aplysia tolloid/ BMP-1-like gene (apTBL-1) was also increased in sensory neurons from pleural-pedal ganglia treated with 5-HT. Moreover, the level of apTBL-1 mRNA was increased in sensory neurons of intact Aplysia that received long-term behavioral training.

\section{MATERIALS AND METHODS}

5-HT treatment of isolated pleural-pedal ganglia and sensitization training. Aplysia californica (Marine Specimens, Alacrity Marine Biological, Redondo Beach, CA) were maintained in artificial seawater, Instant Ocean (Aquarium Systems, Mentor, $\mathrm{OH}$ ) at $15^{\circ} \mathrm{C}$ in $12 \mathrm{hr}$ light/dark cycles for $3 \mathrm{~d}$ before the experiments. The dissection and the treatment of pleuralpedal ganglia were carried out at $15^{\circ} \mathrm{C}$. Animals were anesthetized by injection of isotonic $\mathrm{MgCl}_{2}$. For each experiment, pleural-pedal ganglia were removed from four animals and the connective tissue was trimmed 


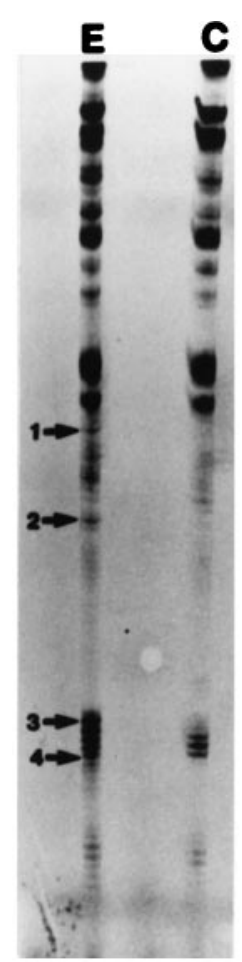

Figure 1. Differential display reverse transcription-PCR (DDRT-PCR). Total RNAs extracted from pleural-pedal ganglia treated with $5 \mu \mathrm{M} 5$-HT for $1.5 \mathrm{hr}(E)$ or without treatment $(C)$ were differentially displayed with an anchored oligo-dT ( $\left.\mathrm{T}_{12} \mathrm{MG}\right)$ and five arbitrary 10-mers (AGCCAGCGAA, GACCGCTTGT, AGGTGACCGT, GGTACTCCAC, and GTTGCGATCC). The bands ( $E$ ) that appeared to be affected by 5 -HT treatments are marked by arrows and numbers.

in $50 \%$ isotonic $\mathrm{MgCl}_{2}$ and $50 \%$ buffered filtered seawater (BFSW; artificial seawater containing $30 \mathrm{~mm}$ HEPES, $\mathrm{pH}$ 7.65) containing streptomycin sulfate $(100 \mu \mathrm{g} / \mathrm{ml})$ and penicillin $\mathrm{G}(100 \mathrm{U} / \mathrm{ml})$. After trimming, the ganglia were equilibrated in BFSW for $2 \mathrm{hr}$ at $15^{\circ} \mathrm{C}$ before treatment with $5 \mu \mathrm{M} 5$-HT for $1.5 \mathrm{hr}$. The control group consisted of 4 matched pleural-pedal ganglia that were incubated in BFSW for the same period of time without 5-HT treatment. For the experiments in which changes in mRNA were examined in sensory neuron clusters, the pleural-pedal ganglia were frozen in liquid nitrogen immediately after the treatment. Sensory neuron clusters were surgically removed from pleural ganglia in a dry ice/propylene glycol/BFSW bath (Noel et al., 1993) and immediately homogenized in the denaturing solution of the RNA isolation kit (Stratagene, La Jolla, CA).

For the behavioral experiments, long-term sensitization training consisted of stimulating one side of an animal with four $10 \mathrm{sec}$ blocks of electrical shocks over a $1.5 \mathrm{hr}$ period (Scholz and Byrne, 1987; Lee et al., 1995). The animals were anesthetized immediately after training. The pleural-pedal ganglia were frozen, and the sensory neuron clusters were removed and processed as described above.

$R N A$ isolation and DDRT-PCR. Total RNA was isolated according to the manufacturer's protocol (Stratagene, La Jolla, CA). Total RNA was dissolved in RNase-free water, and the concentration of RNA was determined by absorbance at $260 \mathrm{~nm}$. Total RNA from 5-HT-treated and control pleural-pedal ganglia was digested with RNase-free DNase I to eliminate trace amounts of chromosomal DNA (MessageClean kit, GenHunter, Brookline, MA). DDRT-PCR (Liang and Pardee, 1992) was performed according to the protocol of the mRNA display system (RNAmap; GenHunter, Brookline, MA). Briefly, single-stranded cDNA was synthesized from $0.5 \mu \mathrm{g}$ of total RNA using Malony murine leukemia virus reverse transcriptase $(100 \mathrm{U})$ in the presence of one of four different anchored oligo-dT primers $(1 \mu \mathrm{M})$ and dNTP $(2.5 \mu \mathrm{M})$ in a final volume of $20 \mu \mathrm{l}$. cDNA $(2 \mu \mathrm{l})$ was amplified with $2 \mathrm{U}$ of AmpliTaq (PerkinElmer) using $\left[\alpha^{-35} \mathrm{~S}\right] \mathrm{dATP}$, dNTPs $(25 \mu \mathrm{M})$, five arbitrary primers, and the same set of anchored oligo-dT primers (see legend to Fig. 1). The thermal cycler was programmed as follows: $94^{\circ} \mathrm{C}, 30 \mathrm{sec} ; 40^{\circ} \mathrm{C}, 2 \mathrm{~min}$; $72^{\circ} \mathrm{C}, 30 \mathrm{sec}$ for 40 cycles. The last cycle was extended at $72^{\circ} \mathrm{C}$ for $5 \mathrm{~min}$ and then kept at $4^{\circ} \mathrm{C}$. The labeled PCR fragments were electrophoresed on a $6 \%$ acrylamide gel containing $6 \mathrm{~m}$ urea and $1 \times$ TBE $(89 \mathrm{~mm}$ Tris-borate, $\mathrm{pH} 8.3,2$ mm EDTA). The differentially displayed bands were cut from the gel and eluted by boiling for $15 \mathrm{~min}$. The DDRT-PCR fragments were precipitated with ethanol and re-amplified with the same set of primers under the same PCR condition except that the dNTP concentration was $250 \mu \mathrm{M}$ and no isotopes were added. The re-amplified PCR fragments were cloned into a TA cloning vector (Invitrogen, San Diego, CA).

$R P A$. The ${ }^{32} \mathrm{P}$-labeled riboprobes to DDRT-PCR clone 2 (150 nucleotides) and Aplysia HSC70 (88 nucleotides) (Kennedy et al., 1992) were synthesized using a MAXIscript kit (Ambion, Austin, TX) in the presence of $\left[\alpha-{ }^{32} \mathrm{P}\right] U T P$. Two micrograms of total RNA were used for hybridization to clone 2 and Aplysia HSC70 riboprobes at $45^{\circ} \mathrm{C}$ overnight. Singlestranded and unbound RNA were digested by a ribonuclease mixture provided by the RPA II kit. The hybridized fragments were precipitated, dissolved in loading buffer, and separated on a 5\% acrylamide gel containing $8 \mathrm{M}$ urea and $1 \times \mathrm{TBE}$. The gels were dried and then exposed to X-ray film. The labeled bands in experimental and control gels were scanned using a computerized image analysis system (DNA Proscan Inc., Nashville, TN). The absorbance readings of clone 2 were normalized to that of HSC. The percent changes between experimental groups and control groups were calculated using normalized readings. Statistical analysis was performed using a two-tailed Student's $t$ test on differences between experimental and matched control values.

cDNA library screening and sequencing. cDNA libraries of Aplysia head ganglia and abdominal ganglia constructed in $\lambda$ ZAP II were provided by Dr. Alexander Kurosky (University of Texas, Medical Branch at Galveston). The libraries were screened with a ${ }^{32} \mathrm{P}$-labeled DDRT-PCR fragment of clone 2. Eight positive cDNA clones were obtained with sizes from 1.8 to $4.2 \mathrm{~kb}$. The screening and excision of plasmids were performed as described previously (Liu et al., 1993). The full-length cDNA in pBluescript (Stratagene) plasmid was sequenced in both directions from overlapping subclones generated by restriction endonuclease digestion. Synthetic primers were used to cover gaps and to verify sequences. The cDNA sequences were assembled and analyzed using GCG software (University of Wisconsin Computer Genetics Group). The deduced amino acid sequence obtained from the cDNA was used to search the GenBank database by means of the BLAST program (Altschul et al., 1990) of the National Center of Biotechnology Information (NCBI).

In vitro translation of apTBL-1. Linearized full-length apTBL-1 cDNA was transcribed into cRNA using a Maxiscript kit (Ambion, Austin, TX). The cRNA was phenol-chloroform-extracted and ethanol-precipitated. The cRNA was translated using rabbit reticulocyte lysate (Ambion) in the presence of $\left[{ }^{35} \mathrm{~S}\right]$ methionine. The translation products were analyzed by $10 \%$ SDS-PAGE. The gel was stained with Coomassie Brilliant Blue and dried. The dried gel was exposed to X-ray film (Kodak).

Production of antibodies against apTBL-1 and immunoblotting. The EcoRI fragment (1953-2556 base) of apTBL-1 was excised from pBluescript and subcloned into the EcoRI site in pMAL-c2 (New England Biolabs, Beverly, MA). The plasmid was transformed into competent $E$. coli BL21 (Novagen), and apTBL-1 (568-770) was expressed as a fusion protein with maltose-binding protein (MBP). MBP-apTBL-1 (568-770) was expressed and purified using Amylose-resin according to the manufacture's protocol (New England Biolabs). Isolated MBP-apTBL-1 was used as the antigen to raise antibodies (Pocono Rabbit Firm, Canadensis, PA). The serum was purified using MBP-Sepharose to remove antibodies against MBP and then applied to MBP-apTBL-1-Sepharose. The bound antibodies were eluted using $4.5 \mathrm{M} \mathrm{MgCl}_{2}$, pH 7.0 (Girault et al., 1989). MBP-Sepharose and MBP-apTBL-1-Sepharose were produced by coupling MBP or MBP-apTBL-1 to CNBr-activated Sepharose 4B (March et al., 1974).

SDS-PAGE was carried out by the method of Laemmli (1970). The proteins were transferred to PVDF membrane in $10 \mathrm{~mm}$ CAPS-NaOH, pH 10.5, containing 10\% methanol. The membrane was blocked with 5\% dry milk (Carnation) in $20 \mathrm{~mm}$ Tris- $\mathrm{HCl}, \mathrm{pH} 7.5$, containing $0.1 \%$ Tween-20 and $150 \mathrm{~mm} \mathrm{NaCl}$ (TTBS) for $1 \mathrm{hr}$ at room temperature. The membrane was then incubated with a polyclonal antibody against apTBL- 1 in TTBS overnight at $4^{\circ} \mathrm{C}$. The blot was incubated with anti rabbit IgG linked to horseradish peroxidase in TTBS for $1 \mathrm{hr}$ at room temperature. Immunodetection was carried out using the ECL system (Amersham). Protein concentration was determined by the method of Bradford (1976) using bovine serum albumin as standard $\left(E_{280}^{1 \%}=6.54\right)$.

Immunofluorescence. Aplysia californica weighing 150-350 gm were 
A.

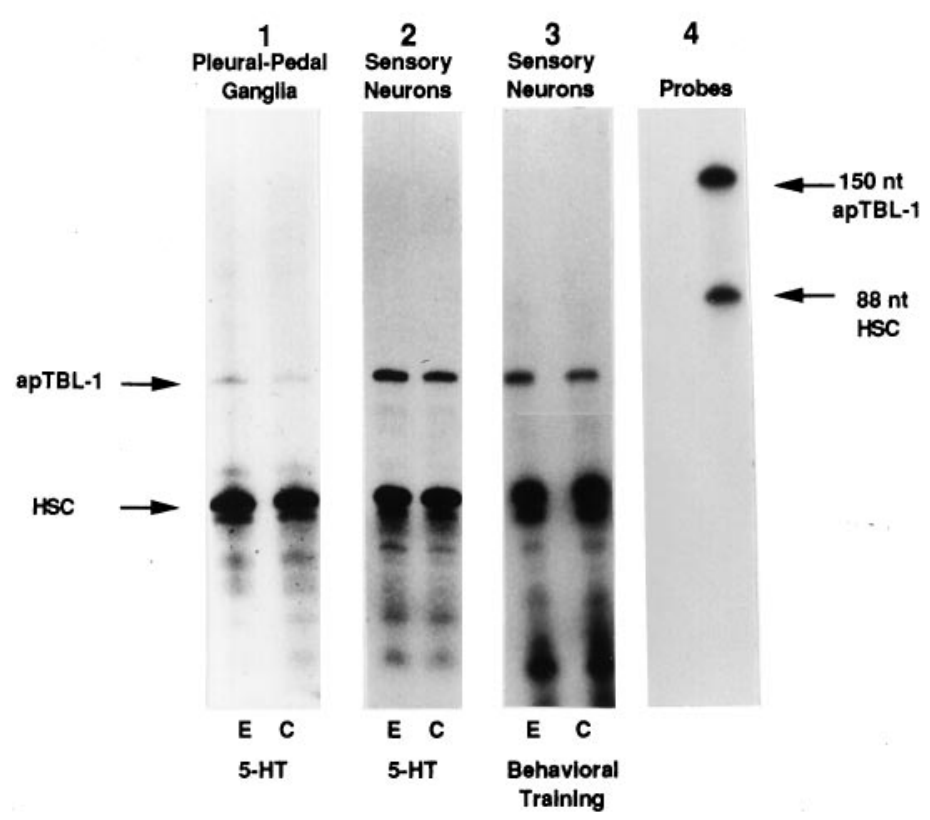

B.

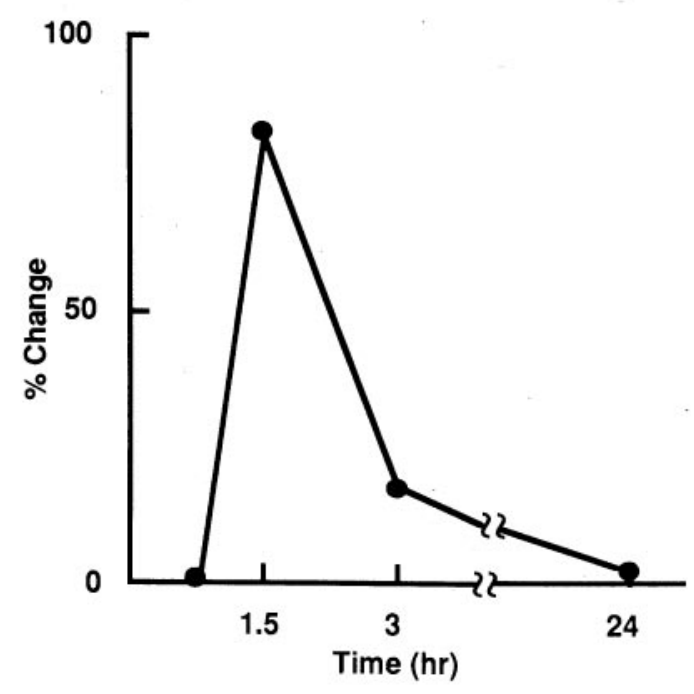

Figure 2. Ribonuclease protection assays of clone 2. A1, Effects of 5-HT on pleural-pedal ganglia. Experimental pleural-pedal ganglia were treated with $5 \mu \mathrm{M} 5$-HT for $1.5 \mathrm{hr}$, whereas matched contralateral control ganglia were untreated. Total RNAs $(2 \mu \mathrm{g})$ from experimental $(E)$ or control $(C)$ pleural-pedal ganglia were hybridized with riboprobes of clone 2 and HSC70 (heat shock cognate protein). A2, Effects of 5-HT on sensory neurons. Total RNAs were extracted from sensory neurons of pleural-pedal ganglia treated with $5 \mu \mathrm{M} 5$-HT for $1.5 \mathrm{hr}(E)$ or without treatment $(C)$. $A 3$, Effects of behavioral training on sensory neurons. Total RNAs were extracted from sensory neurons of pleural-pedal ganglia from the stimulated side $(E)$ or unstimulated side $(C)$ of animals. The size and purity of the probes are shown in $A 4$. $B$, The time course of clone 2 mRNA change. Pleural-pedal ganglia were treated with $5 \mu \mathrm{M} 5$-HT for 0.75 and $1.5 \mathrm{hr}$, and sensory clusters were isolated and processed for RPA as described in Materials and Methods. After $1.5 \mathrm{hr}, 5$-HT was removed by washing with BFSW and ganglia were kept in BFSW. At 1.5 and $22.5 \mathrm{hr}$ after removing 5-HT (time 3 and $24 \mathrm{hr}$ ), sensory clusters were isolated and processed for RPA.

anesthetized, and the attached pleural-pedal ganglia were removed. The ganglia were fixed for $3 \mathrm{hr}$ at room temperature in $4 \%$ paraformaldehyde in $\mathrm{PBS}(0.85 \% \mathrm{NaCl}$ and $10 \mathrm{~mm}$ sodium phosphate, $\mathrm{pH} 7.4)$ containing $30 \%(\mathrm{w} / \mathrm{v})$ sucrose and rinsed overnight at $4^{\circ} \mathrm{C}$ in $30 \%$ sucrose-PBS. Ganglia were sectioned with a nominal thickness of $16 \mu \mathrm{m}$ using a cryostat (Zhang et al., 1991). Antibody penetration was enhanced by dehydrating and rehydrating the sections through a graded series of ethanol solutions $(10-50 \%)$. To reduce background staining, the sections were treated with $0.3 \% \mathrm{H}_{2} \mathrm{O}_{2}$ for $10 \mathrm{~min}$ and incubated in $2 \%$ normal goat serum for $30 \mathrm{~min}$ (Jonas et al., 1996). All sections were incubated in primary antibody $(1: 100$ in $0.1 \%$ Triton $\mathrm{X}-100)$ overnight and then incubated in rhodamine-conjugated goat anti-rabbit antisera (Cappel; 1:50 in $0.1 \%$ Triton X-100) for $0.5 \mathrm{hr}$ and coverslipped using Aqua Polymount (Polyscience). When the same dilution of preimmune serum was used as the primary antibody, no staining was observed.

\section{RESULTS}

Identification of mRNAs the synthesis of which was increased in pleural-pedal ganglia by treatment with 5-HT

DDRT-PCR (Liang and Pardee, 1992) was used to search for mRNA molecules the synthesis of which was altered by treatment of pleural-pedal ganglia with 5-HT. Total RNA was isolated from four control pleural-pedal ganglia and four experimental contralateral pleural-pedal ganglia that had been treated with 5-HT for $1.5 \mathrm{hr}$. Such treatments lead to long-term ( $24 \mathrm{hr})$ facilitation of the connections between pleural sensory neurons and pedal motor neurons (Emptage and Carew, 1993; Zhang et al., 1996). Different anchored oligo-dTs were used to prime cDNA synthesis. Arbitrary 10-mers plus the same anchored oligo-dTs were used for PCR. A subpopulation of mRNAs with sizes ranging from 100 to $500 \mathrm{bp}$ was resolved on acrylamide gels. Changes in levels of mRNA appeared as changes in labeled DDRT-PCR fragments. Figure 1 illustrates ${ }^{35} \mathrm{~S}$-labeled fragments generated by DDRT-PCR from total RNA of 5-HT-treated $(E)$ and control $(C)$ pleural-pedal ganglia. Four bands that appeared in the experimental group $(E)$ were not observed in the control group $(C)$. The differentially displayed PCR fragments were cut from the gel and re-amplified by the same sets of primers. The four PCR fragments were subsequently cloned into a TA cloning vector (Invitrogen) and named clone 1 , clone 2 , clone 3 , and clone 4 .

\section{5-HT treatment and long-term behavioral training increase clone 2 mRNA in the sensory neurons of pleural-pedal ganglia}

Ribonuclease protection assays (RPA) were used to confirm the results of the DDRT-PCR experiments. Riboprobes were made to clone 1 , clone 2 , clone 3 , and clone 4 by in vitro transcription. A riboprobe of heat shock cognate protein (HSC70), the mRNA level of which was not affected by treatment with 5-HT, was included in the hybridization solution as an internal control for normalization (Kennedy et al., 1992; Hu et al., 1993). The riboprobes were used in RPAs to measure the levels of mRNA in pleural-pedal ganglia treated with 5 -HT for $1.5 \mathrm{hr}$. Clone 2 mRNA increased significantly $(60 \pm 13 \%$, mean \pm SEM, $p<$ $0.05, n=8$ ) in pleural-pedal ganglia treated with 5-HT (Fig. 2A1). The mRNA levels of the other three DDRT-PCR clones did not appear to be affected by 5-HT and were not analyzed further.

To determine whether the change in clone 2 mRNA from 
pleural-pedal ganglia also occurred in the mRNA from sensory neurons, total RNA was isolated from sensory neuron clusters and RPAs were performed using clone 2 riboprobe. Treatment of ganglia with 5-HT for $1.5 \mathrm{hr}$ resulted in a significant increase of clone 2 mRNA $(82 \pm 22 \%, p<0.02, n=10)$ obtained from sensory neurons (Fig. 2A2). Shorter treatment of 5-HT (45 min) had little effect on apTBL-1 mRNA, and the effect of 5-HT (1.5 hr) on apTBL-1 mRNA did not persist for very long after the 5-HT treatment (Fig. $2 B ; 3 \mathrm{hr}, 17 \pm 8 \%, p<0.12, n=6$ ).

Because effects of 5-HT on facilitation are mediated by increases in cAMP, we also investigated whether increasing cAMP would increase clone 2 mRNA. Treatment of ganglia with 8-(4-chlorophenylthio)-cAMP and 7-deacetyl-7-(O-Nmethylpiperazino)- $\gamma$-butyryl-forskolin increased clone 2 mRNA from sensory neurons $(85 \pm 64 \%, p<0.05, n=7$ and $89 \pm 45 \%$, $p<0.036, n=6$, respectively). The changes in levels of mRNAs were calculated without using HSC for normalization because these treatments significantly elevated the level of HSC mRNA.

We also examined whether mRNA levels of clone 2 were affected by behavioral training. Long-term sensitization training consisted of stimulating one side of an animal with four blocks of shocks over a $1.5 \mathrm{hr}$ period. Previous studies have shown that this training procedure leads to significant long-term enhancement of the defensive reflex as well as presynaptic facilitation on the trained side compared to the untrained side (Scholz and Byrne, 1987; Lee et al., 1995). The sensory neuron clusters were removed immediately after training. Clone 2 mRNA was significantly increased in the pleural sensory neurons (Fig. 2A3) from the trained side compared to the contralateral control side $(29 \pm 8 \%, p<$ $0.03, n=10$ ).

\section{Clone 2 cDNA encodes an Aplysia Tolloid/BMP-1-like protein}

The DDRT-PCR fragment that was located at the $3^{\prime}$-untranslated sequence of the mRNA gave little information about the identity of the protein. To determine the protein sequence for clone 2, cDNA libraries of Aplysia head and abdominal ganglia were screened using a ${ }^{32} \mathrm{P}$-labeled clone 2 fragment (150 bp) as a probe. Eight separate positive clones were obtained with different insert sizes of $1.5-4.2 \mathrm{~kb}$. The longest cDNA clone $(4.2 \mathrm{~kb})$ was sequenced in both directions, and it contained $5^{\prime}$-untranslated sequence before an initiation methionine and a $3^{\prime}$-polyA tract, suggesting that it was a full-length cDNA. The DDRT-PCR clone 2 fragment was located between nucleotides 3463 and 3591 (Fig. 3 ). The deduced amino acid sequence of clone 2 was found to be $\sim 45 \%$ identical to a developmentally regulated family of genes that includes the Drosophila tolloid gene and the human bone morphogenetic protein-1 (BMP-1) gene. Hence, the DDRT-PCR clone 2 was named Aplysia tolloid/BMP-1-like protein (apTBL-1).

\section{Tissue distribution of apTBL-1 mRNA}

RPA analysis was used to examine the tissue distribution of apTBL-1 mRNA (Fig. 4). apTBL-1 mRNA was detected in the CNS, heart, gill, body wall, and kidney. mRNA of apTBL-1 was not observed in hepatopancreas, ovotestis, or penis (Fig. 4). The level of apTBL-1 mRNA was particularly high in sensory neurons (SN) compared to that in pedal ganglia (PD) or CNS. Furthermore, a single $4.4 \mathrm{~kb}$ mRNA band was detected by Northern blot analysis with similar tissue distribution to that shown in Figure 4 (data not shown).

\section{Deduced amino acid sequence of Aplysia Tolloid/BMP-1-like protein}

The full-length cDNA of $4161 \mathrm{bp}$ contained an open reading frame of $3210 \mathrm{bp}$ encoding 1070 amino acids with a predicted molecular weight of 120,682 (Fig. 3). The predicted polypeptide of apTBL-1 is highly hydrophilic with 406 charged amino acids, resulting in a calculated isoelectric point of 6.2. Hydropathy analysis indicates that the deduced protein sequence of apTBL-1 contains an N-terminal hydrophobic region with the characteristics of a signal peptide for secretion to the extracellular space. A possible cleavage site for the signal peptide exists at $\mathrm{Ala}^{39} / \mathrm{Glu}^{40}$ (von Heijne, 1984). Seven potential glycosylation sites are contained in the amino acid sequence. Tandem repeats of mRNAdestabilizing signals (ATTTA) are located between nucleotides 3962 and 3973 (Shaw and Kamen, 1986).

apTBL-1 mRNA has two separate consensus Kozak sequences (GCCAUGG) for the translation initiation methionine (Kozak, 1987). The first methionine is at the beginning of the signal peptide, and the second methionine is 94 amino acids after the end of the signal peptide (Fig. 3). To establish which methionine is used, in vitro translation of the full-length cDNA was performed. Two major translation products were observed at $\sim 120$ and $130 \mathrm{kDa}$ (Fig. 5). Furthermore, immunoblot analysis of pleural-pedal ganglia using antibody against apTBL-1 also revealed two bands of molecular weight 120,000 and 130,000 (Fig. $6)$. This result suggests that at least two forms of apTBL-1 are present in Aplysia neurons. The existence of two putative start sites in apTBL and two forms of apTBL-1 present in tissue raises the possibility that one form might be secreted whereas the other, lacking a signal peptide, would be retained in the cytoplasm.

\section{Immunolocalization of apTBL-1 in pleural ganglia}

The cellular distribution of apTBL-1 was examined with the same antibody as that used for the immunoblot experiment described above. apTBL-1 immunoreactivity was observed throughout the pleural ganglion (Fig. 7). Most of the immunoreactive protein appeared to be localized in relatively large granules or patches in neurons. In cell bodies of sensory neurons, the staining appeared to be distributed in a single layer around the nucleus. Not all sensory neurons were labeled, however. In larger cells within the ganglion, the immunoreactive granules appeared to be distributed homogeneously throughout the cytoplasm (not shown). The stained patches and granules appeared to have a different distribution than pigment granules, which tend to be concentrated in one pole of the cell body. Although evidence was described above for the existence of a cytoplasmic form of apTBL-1, we could not detect staining in the cytoplasm, perhaps due to a low concentration of apTBL-1 in the cytoplasm. The immunoreactive protein was also distributed throughout the neuropil. It was not possible to identify the cell types labeled in the neuropil by the antibody. Staining in the neuronal cell bodies suggested that their processes in the neuropil were labeled, but glial cells in the neuropil could also contain the immunoreactive protein.

\section{Domain structures of Aplysia Tolloid/BMP-1-like protein and other members of the family}

The deduced amino acid sequence of the apTBL-1 protein contains a metalloprotease domain, five CUB (Complement subcomponents $\mathrm{C} 1 \mathrm{r} / \mathrm{C} 1 \mathrm{~s}$, Uegf, BMP-1) domains, and two epidermal growth factor (EGF)-like sequences (Figs. 3, 8). The metalloprotease domain is similar to a crayfish metalloprotease, astacin. The protease domain contains an active site pentapeptide motif 


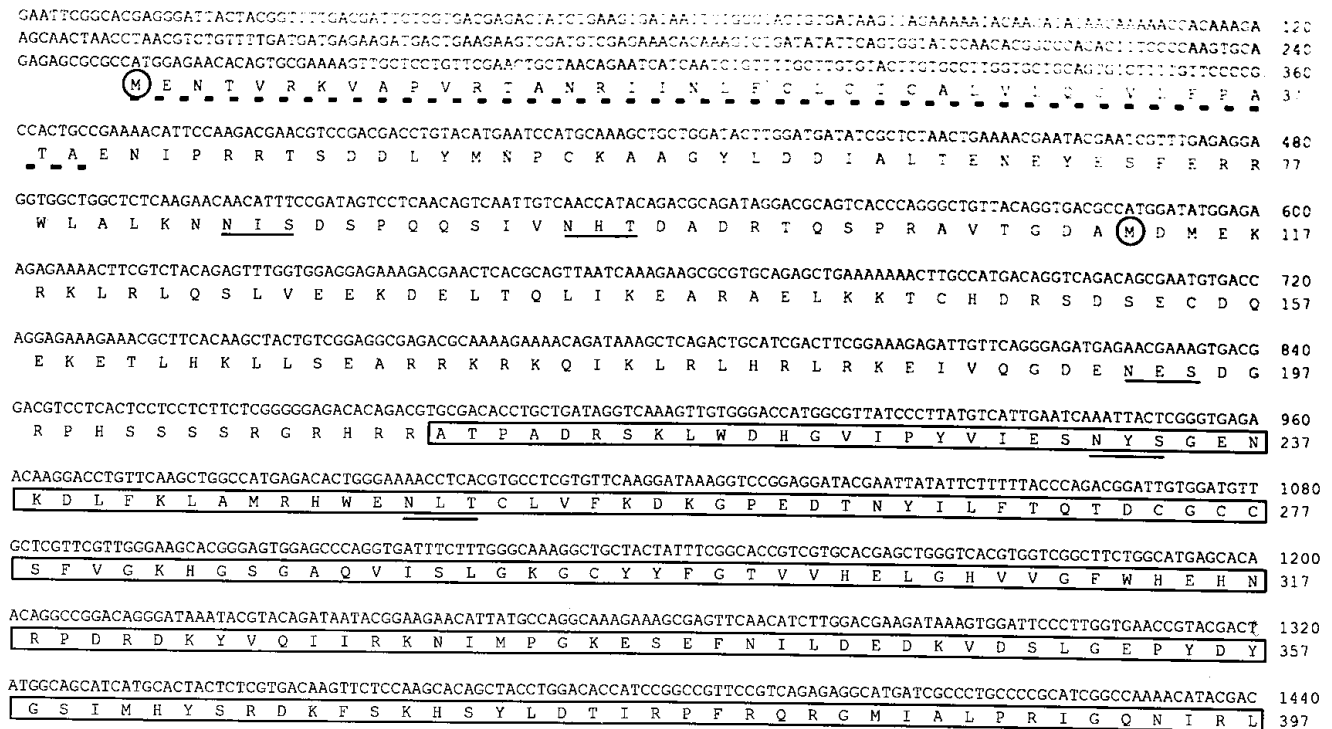
TCAATGATGGGGACGTACGACAGACCAACAAACTCTACAAGTGCCCTACTTGTGGCCGCACCGTGATGGAATCAAAGGGCACGATTAGCCCCGACTCAGGGATACGAGGCGAAAAGACGT 1560

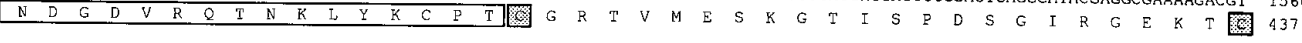
GCCAATGGAGGATCATAGCCTCTCACGGGGAGCGGATCCAGCTGAGCCTGACCCGACTTGACCTCAGTAACTGTGACACAGACTACGTGGAGGTCAGGGATGGACATTTTGTCGGCTCTC 1 680 Q W TCAGTTTGGGCAAATTCTGTGGGAAGAAGATCCCCCCGCCCATGATCTCCTCCGGCACTCGCCTCTGGGTGGAGTACAAGTCAAGGGCGGCGCGCCGGGAGGCTTTCCAGGCCGCTTTTG 1800

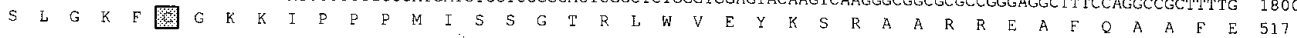
AGGCTATATGCGGTGGTACATGCCTGGACCTGAAGGCTTCCTCAACAGTCCCGCTTATCCGGATGAGTATGGCAGTGATAAAGTCTGCGAGTGGGTCATCACTGTGAGAGAGGGATATC 1920 A I AAGTGGCTCTAGAGTTCGCCACTTTCGAGACGGAATTCGACCCTGACTGTGCCTACGACTACGTAGAGATCCGAGATGGTGACACAAAAGACTCGCCTCTTGTGGGTACATATTGCGGGA 2040 $\begin{array}{llllllllllllllllllllllllllllllllllllllllll}V & A & L & E & F & A & I & E & E & T & E & F & D & P & D & {[C} & A & Y & D & Y & V & E & I & R & D & G & D & T & K & D & S & P & L & V & G & T & Y & G & G & T & 597\end{array}$ CCCGCACGCCTCCTAACGCGATCTCCACGTCGCGCCATCTCTATGTCAAGTTTGTCAGTGATGAGTCCATGCAGAAAGGTGGCTTCTCTGCTTCATATCTAGAAGAGGTGGACGAGTGTG 2160 $\begin{array}{llllllllllllllllllllllllllllllllllllllll}R & T & P & P & N & A & I & S & T & S & R & H & L & Y & V & K & F & V & S & D & E & S & M & Q & K & G & G & F & S & A & S & Y & L & E & E & V & D & E & C & E\end{array}$ AGGGTGARGACCACGGCTGTGAGCACGTGTGTGTGAACACTCTAGGCAGCTACGAGTGCACGTGCAAGATTGGATATGAGCTGCATTCGGACGGGAAGAAATGTGAAAAGGCGTGCGGGG 2280

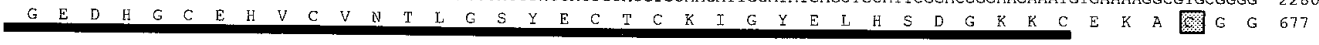
GTIACTTGGACGCACCCAGTGGAACCATCTCCTCCCGTCCTTCCCTGACCTCTACCCCCCAGACAAGAACTGTGTCTGGCACATCAGCGCGCCCAAGGGACACACCCTCACCGTGAACT 2400

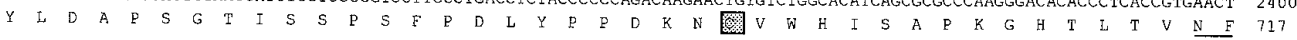
TTACTCATATGGATCTGGAGTGGAGGGGGATGAATGTGAATTAGACTTCGTGCGTGTGACAAACGTCGTTGGTAATAAGGAAAGACTACAAGGCCAGTACTGTGGCTTCATGGCCCCGC 2520

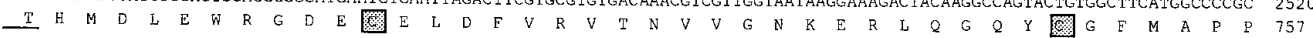
CCTCAATTACGTCACTTAGCAACGAGCTGAGAATAGAATTCCGGTCGGATGACACTTTGCAAAAGACAGGATTCTCTATGGACTATGTGGCAGACGTGGACGAGTGTGCCAGCAGCAATG 2640

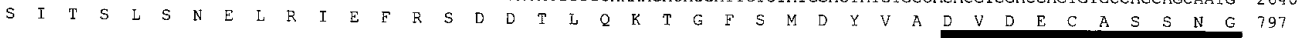
GCGGCTGCAAGCACATCTGTGAGAACACTGTGGGAAGCTTCCACTGTTCGTGTCGIGAGGGTTTCATCCIGGCCGATGACGAGAAGAGCTGCAAGGAGGGCGGCTGCCATTATGAGGTGA 2760

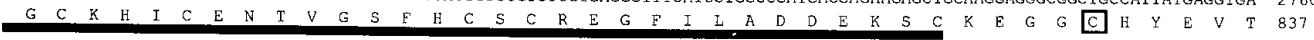
CAGATACCAAGGGGGTCATCCAGAGCCCAGATTACCCAAGCTTCTACCCGGCCAGGCGAGACTGTGAGTGGCATTTCACCACAGCACCAGGACACGTTGTCCGTCTCATATTCACGGATT 2880

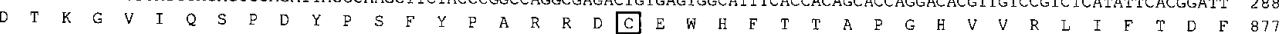
TCCAGGTTGAGCCTCACAGGACTTGTAGGTACGATCACGTTGAGGCGTTTGACGGTGCAAATATTCAGGCACCACAGAITGGCAAATACTGCGGCTCAGAAAAGCCTGCACCAATCATAT 3000 Q $V$ V E CTTCCGAAAACACGTTGACCTTGACCTTCCTCTCTGACACGTCTGTGCAGCGGAAAGGATTTAGAGCCCGTCATGACACTGTGTGTCAGTCGTCACCCACAGCTACGAGTGCCCCCAAGA 3120

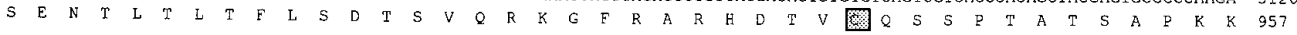
AGATTCTGTCCCACGTCCTGTACGGCAGCAAACCCTACGACAACAGACAGAACTGCTCCTGGAACATCCAGGCGCCCGAGGGCCAGCACGTGGAGCTCAGGTTCACAGCCTTTGAGATTG 3240

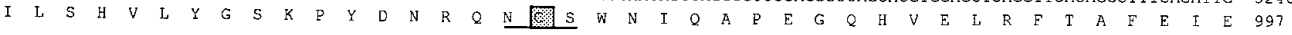
AACAACAGTCCAGATGCCTGTACGACTACGTGGCTGTCTACGATGGGCCGACGGAGAATGACCTCGTCCTCGGCAAGTTCTGTGGGAATCAGGTCCCAAGCCCTATCGTCTCCAGTACAC 3360

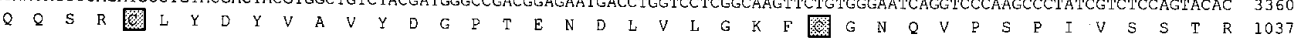
GCAGTCTTCTCGTTCGCTTCCGCTCTGACGATACGATCAAATCTGGAGGCTTCAGCGCCACCTATCGCATTGCAGATGACACGGACACACAGTGGATCTGCTGAGCCAGTGAAAACAAAA 3480

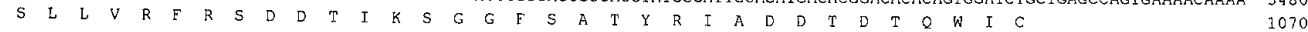

AGGAGCAAAGCCTACGGGGTTCAACAATTGATGAANTGTTACTGATTATATTGAAAGCAAATATGCAGTTITCATGTTGAACTCTGGTAAATGAAAAGTCTTCCCCCCAGCAAGACTGTA 3600 CTGAACTGTTATCTATCGCCTATTATTATCACCATCCTAACAAGATCATGTATAATAATCAAATCAGAGTCTCTTAATATTAGGCCTACGTTACCCATATTGCACACGACCGACTTAGAG 3720

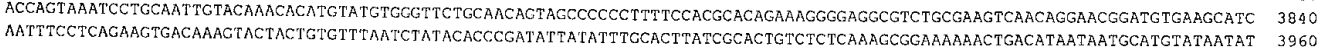
AAAT A AATTTAAATATAATGCCTCTTAMATAAAGA TCGGTGTITCCTCTAAATCCACGAACAAACAAATGCATGGGATGACGTGGTGTATATGACGTGTCTCACTCTGACAGGCCCTAA 4080 GACAACANTGTATTGTATATATTTTACTTCTGGTCGTGATAAACTCGATATTACTCLTAAAAAAAAAAAAAAAMAAAAAA

Figure 3. Nucleotide and deduced amino acid sequences of apTBL-1 cDNA. apTBL-1 cDNA contains two possible translation initiation methionines (circled). The deduced amino acid sequence encodes a potential signal peptide at the $\mathrm{N}$ terminus (underlined with broken lines). Also, the deduced amino acid sequence contains the sequence homologous to the crayfish astacin family of metalloproteases (boxed), two 40-amino-acid repeats with EGF-like sequences (thick underlines), and seven potential glycosylation sites (thin underlined). The four cysteine residues for each CUB (complement subcomponents $\mathrm{C} 1 \mathrm{r} / \mathrm{C} 1 \mathrm{~s}$, Uegf, BMP-1) repeat are enclosed in stippled or open boxes for alternate CUB repeats. The poly[A] signal sequences and RNA destabilization signal sequences are underlined with thin dashed lines. The nucleotide sequence of apTBL-1 cDNA has been submitted to GenBank under accession number U57369. 
Figure 4. Distribution of apTBL-1 in various tissues of Aplysia. Total RNA ( $2.5 \mu \mathrm{g}$ for pleural sensory neurons, $4 \mu \mathrm{g}$ for other tissues) from Aplysia tissues was isolated and analyzed by RPA using the ${ }^{32} \mathrm{P}$-labeled apTBL-1 riboprobe discussed in Materials and Methods. The sources of RNA were as follows: $P D$, pedal ganglia; $S N$, pleural sensory neurons; $C N S$, central nervous system; $G L$, gill; $H T$, heart; $K N$, kidney; $B W$, body wall; $H P$, hepatopancreas; $P N$, penis; $O T$, ovotestis.
A

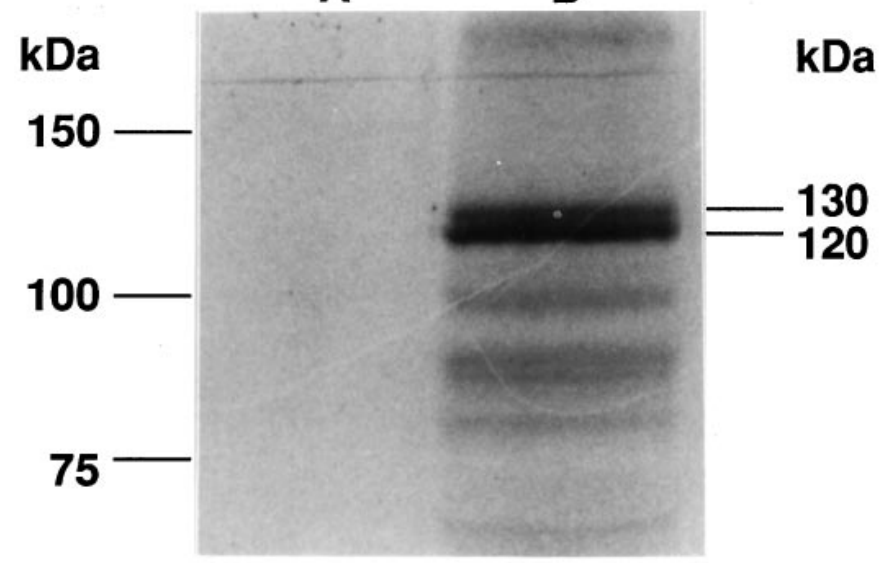

Figure 5. In vitro translation of apTBL-1. In vitro translation products with $(B)$ or without $(A)$ capped cRNA of full-length apTBL-1 cDNA in the presence of $\left[{ }^{35} \mathrm{~S}\right]$ methionine. The Perfect Protein Marker (Novagen) was used as a molecular weight marker.

$\mathrm{HEXXH}$ that is presumably the $\mathrm{Zn}^{2+}$-binding site (Dumermuth et al., 1991). Members of the tolloid/BMP-1 gene family are initially made as precursor molecules with an $\mathrm{N}$-terminal signal peptide and a proregion of varying size. The proregion is cleaved at RXXR immediately adjacent to the metalloprotease domain (Shimell et al., 1991). The N-terminal and C-terminal sequences are the least similar sequences among the different members of the family (Fig. 8). The N-terminal region of apTBL-1 corresponding to amino acids 47-68 shares similarity with tolloidrelated-1 (tlr-1) protein $(59 \%, 142-163)$ and sea urchin (Strongylocentrotus purpuratus) suBMP-1 (71\%, 30-50) but not with other members of the family (Hwang et al., 1994; Nguyen et al., 1994). The lengths of the $\mathrm{N}$-terminal region before the protease domain vary in different isoforms and different species. Tissue- and stagespecific regulation of metalloproteases might be dependent on the length and sequence of the N-terminal regions of the different members of tolloid/BMP-1 family.

CUB and EGF-like domains are believed to be regions where proteins bind to one another (Appella et al., 1988; Bork and Beckmann, 1993). The CUB domain is widespread in developmentally regulated proteins involved in embryogenesis and organogenesis (Bork and Beckmann, 1993). The CUB domain has four cysteines regularly spaced and might form $\beta$-barrel structures similar to immunoglobulins. The CUB domains appear to bind calcium, which might promote interactions with other proteins (Bork and Beckmann, 1993). EGF-like domains are conserved in cell surface proteins, such as Drosophila notch, C. elegans LIN, laminin, tissue plasminogen activator (tPA), TGF- $\alpha$, and coagulation factors VII, IX, X, and XII (Bork and Beckmann, 1993). The EGF-like domain might be involved in receptor ligand binding (Appella et al., 1988). This domain contains a consensus sequence for the posttranslational $\beta$-hydroxylation of arginine or aspartic acid, which can form a high-affinity calcium-binding site
PD SN CNS GL HT KD BW HP PN OT
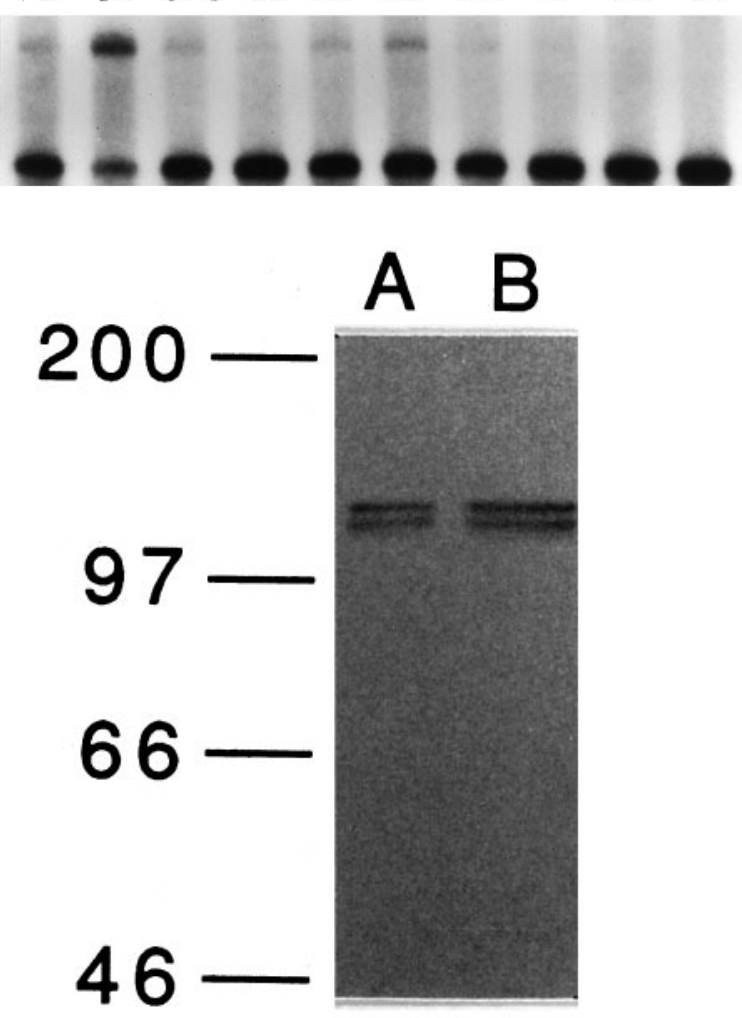

Figure 6. Immunoblot analysis of apTBL-1 proteins in pleural-pedal ganglia. Pleural-pedal ganglia of Aplysia californica were isolated and homogenized in $20 \mathrm{~mm}$ Tris- $\mathrm{HCl}, \mathrm{pH} 7.5$, containing $1 \mu \mathrm{M}$ leupeptin, $1 \mu \mathrm{M}$ chymostatin, $1 \mu \mathrm{M}$ pepstatin, $1 \mu \mathrm{M}$ bestatin, $5 \mathrm{~mm}$ EGTA, $5 \mathrm{~mm}$ EDTA, and $1 \mathrm{~mm}$ PMSF. The homogenate was centrifuged at $800 \times g$ for $5 \mathrm{~min}$. Immunoblot of the supernatant was performed as described in Materials and Methods. Ten micrograms of total protein $(A)$ and $20 \mu \mathrm{g}$ of total protein $(B)$ were used for SDS-PAGE. Prestained molecular weight markers (Amersham) - myosin $\left(M_{\mathrm{r}}=200,000\right)$, phosphorylase $b\left(M_{\mathrm{r}}=97,400\right)$, bovine serum albumin $\left(M_{\mathrm{r}}=66,000\right)$, and ovalbumin $\left(M_{\mathrm{r}}=46,000\right)-$ were used.

(Rees et al., 1988). The numbers of CUB and EGF domains in a specific protein vary in different members of the family (Fig. 8). The different arrangements of these putative protein interaction domains might indicate that members of this family bind to a variety of proteins in homomeric and heteromeric complexes.

\section{DISCUSSION}

Using the technique of DDRT-PCR, an Aplysia tolloid/BMP-1like cDNA clone was isolated. Sensitization of intact animals and treatments of pleural-pedal ganglia that mimic the effects of training (5-HT and agents that elevate cAMP) increased the level of apTBL-1 mRNA in sensory neurons. A long duration treatment of 5-HT was required to affect the mRNA and the effect did not persist very long after the 5-HT treatment (Fig. 2B). The increase in levels of mRNA for apTBL-1 that we observed could be due to increased transcription or decreased turnover of mRNA. Nuclear run-off experiments will be required to determine the exact mechanism of change in apTBL-1 mRNA levels produced by 5 -HT treatment and behavioral training.

apTBL-1 protein was concentrated in large granules or patches in the cell bodies of sensory neurons and other neurons in the pleural ganglion. Not all sensory neurons were labeled, however. Additional studies will be necessary to identify the organelles 


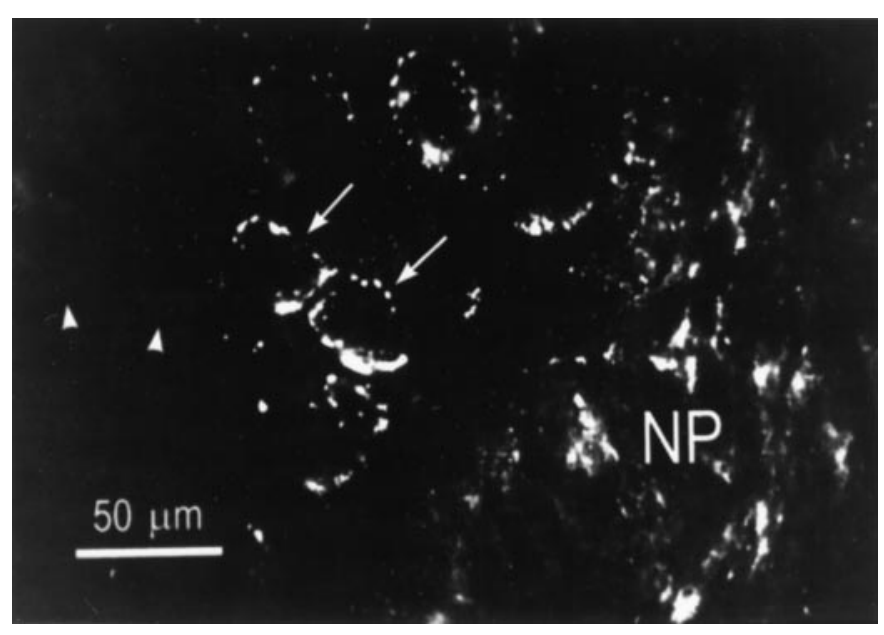

Figure 7. Immunolocalization of apTBL-1 in the pleural ganglion. The antibody directed against apTBL-1 protein produced punctuate staining in numerous cell bodies throughout the pleural ganglion, including sensory neurons (arrows). However, not all neurons in the sensory cluster were labeled (arrowheads). There was also staining in the neuropil $(N P)$ and processes passing through the neuropil. In these relatively thick sections, it was not possible to identify stained structures in the neuropil.

containing the apTBL-1 protein. The labeling pattern is consistent with localization of apTBL-1 in organelles of the secretory pathway, such as the Golgi apparatus and secretory vesicles. Therefore, it is likely that much of the labeling in the neuropil is due to the presence of transported organelles in neuronal processes. If confirmed, this conclusion would support the hypothesis that apTBL-1 is secreted into the extracellular space where it will activate TGF- $\beta$ (see below). It was not possible to distinguish intracellular label from extracellular label in the neuropil of these relatively thick tissue sections. Further studies of the location of apTBL-1 and changes in levels of apTLB-1 will be required to establish the functional role of the protein in learning and memory.

Injury responses elicited by severing nerves or removal of ganglia from Aplysia are known to cause a number of neurophysiological and biochemical changes (Alberini et al., 1994; Walters and Ambron, 1995). Because tolloid/BMP-1 have roles in development, they might also have roles in injury responses. Our observation that mRNA of apTBL-1 increased after behavioral training suggests that apTBL-1 plays a role in sensitization and that injury is not required to cause the observed changes in apTBL-1. However, this issue requires additional research in the future because injury might also cause changes in apTBL-1.

Training and treatments that mimic behavioral training alter mRNAs of Aplysia genes in addition to apTBL-1, including BiP, calreticulin, CCAAT enhancer binding protein (apC/EBP), clathrin, and calmodulin (Zwartjes et al., 1991; Kennedy et al., 1992; Kuhl et al., 1992; Hu et al., 1993; Alberini et al., 1994). This diversity of mRNAs indicates that a wide spectrum of genes and cellular processes are regulated during learning. The magnitude of the effects of training on these mRNAs has varied greatly, ranging from a $35 \%$ change in the mRNA of clathrin to severalfold changes in the mRNAs of BiP and calreticulin (Kennedy et al., 1992; Kuhl et al., 1992; Hu et al., 1993). In the present study, we observed an $82 \%$ change in the mRNA of apTBL- 1 in sensory neurons exposed to 5 -HT for $1.5 \mathrm{hr}$. Some of the variation that has been observed in the changes in mRNAs is most likely due to differences in experimental conditions used to study the mRNAs.
For example, clathrin mRNA was studied in whole pleural ganglia after $1.5 \mathrm{hr}$ treatments with 5-HT plus IBMX, whereas the BiP and calreticulin mRNAs were studied in pleural sensory neurons $24 \mathrm{hr}$ after animals had received $4 \mathrm{~d}$ of sensitization training.

The sequence of apTBL-1 was similar to that of a developmentally regulated gene family, the most conserved members of which are Drosophila tolloid (tld) and bone morphogenetic protein-1 (BMP-1), from various species such as mouse, human, Xenopus, and sea urchin. The Drosophila tolloid gene is involved in dorsal ventral patterning during development (Shimell et al., 1991). Bone morphogenetic proteins were initially isolated as a group of proteins that induce bone formation when implanted into ectopic sites of mice (Wozney et al., 1988). BMP-1/tolloid genes have also been found to be differentially expressed in adult tissues (Takahara et al., 1994). The tissue distribution of apTBL-1 indicates that it also is differentially expressed in adult Aplysia tissues, being present in the CNS, kidney, gill, and heart.

\section{Interaction of Tolloid/BMP-1-like molecules with TGF- $\beta$ and procollagen}

There is genetic evidence that tolloid enhances the activity of decapentaplegic (dpp), which codes for a TGF- $\beta$-like molecule in Drosophila (Shimell et al., 1991; Ferguson and Anderson, 1992). Other evidence for an association between tolloid/BMP-1 and TGF- $\beta$-like molecules is the copurification of BMP-1 with the TGF- $\beta$-like molecules BMP-2 and BMP-3 (Wozney et al., 1988). There are more than 25 members of the TGF- $\beta$ superfamily that mediate a variety of functions in normal growth and development. TGF- $\beta$ molecules are initially synthesized as larger secretory precursors containing a signal sequence. The propeptide region is cleaved by proteolysis to release the mature factors that form the active dimers (Kingsley, 1994). The availability of proteases, like tolloid/BMP-1, to regulate the activity of TGF- $\beta$ like molecules might be an important factor in the regulation of growth and differentiation by TGF- $\beta$ (Thomsen and Melton, 1993).

Recently, BMP-1 was shown to be identical to procollagen C-proteinase (Kessler et al., 1996). Collagens are synthesized as procollagens with $\mathrm{N}$ - and $\mathrm{C}$-terminal propeptides that must be cleaved to collagen fibrils (Kühn, 1987). Procollagen C-proteinase (PCP) cleaves the carboxyl propeptides of procollagens I, II, and III to yield the major fibrous components of the extracellular matrix (Kühn, 1987). This suggests that tolloid/BMP-1-like molecules might play two roles in extracellular space: activation of TGF- $\beta$ s and processing of procollagens. Interestingly, members of the TGF- $\beta$ family have been shown to have a broad range of effects on components of the extracellular matrix (Massagué, 1990).

\section{Possible roles of apTBL-1 in long-term memory}

Morphological changes in the presynaptic sensory neurons and other changes in the postsynaptic motor neurons are associated with long-term sensitization, and long-term facilitation of the sensory-motor connections (Bailey and Chen, 1988; Barzilai et al., 1989; Bailey et al., 1992; Mayford et al., 1992; Peter et al., 1994; Trudeau and Castellucci, 1995). It is possible that the morphological changes that occur as a result of long-term sensitization training involve proteases and growth factors like TGF- $\beta$ s. The mRNA level of tissue-plasminogen activator (tPA), an extracellular serine protease that converts plasminogen to plasmin, is increased by brain activity-dependent events, such as seizure, 


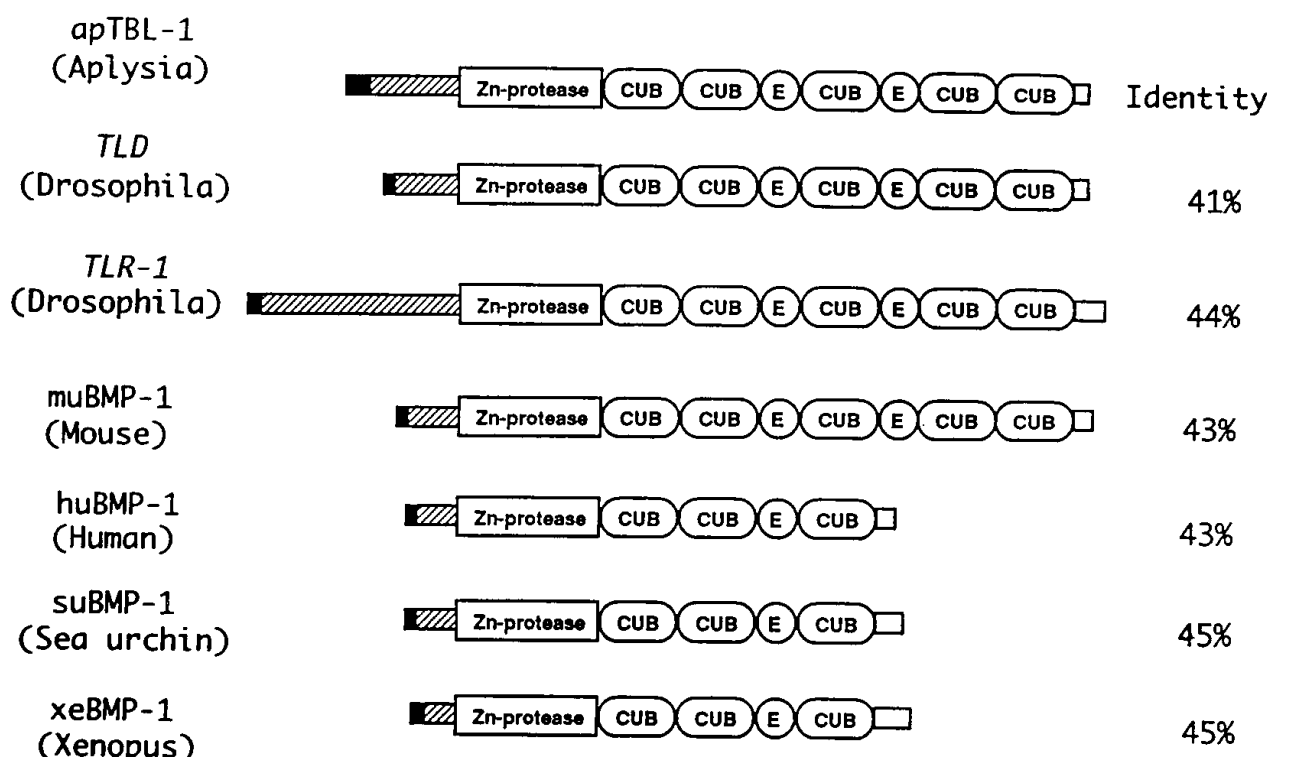

Figure 8. Comparison of the domain structures of tolloid/BMP-1-like proteins. The tolloid/BMP-1 gene family includes Aplysia TBL-1, Drosophila tolloid (Shimell et al., 1991), tolloid-related-1 (Nguyen et al., 1994), mouse BMP-1 (Fukagawa et al., 1994), human BMP-1 (Wozney et al., 1988), sea urchin BMP-1 (Hwang et al., 1994), and Xenopus BMP-1 (Maeno et al., 1993). The potential signal peptide is represented by a black box, and propeptides are represented by hatched boxes. The metalloprotease domain, CUB repeats, and EGF-like repeats are marked accordingly. The C-terminal nonhomologous sequences are represented by open boxes. The group of apTBL-1, tolloid, tolloid-related-1, and muBMP-1 contains five CUB repeats and two EGF-like repeats, and the group of huBMP-1, suBMP-1, and xeBMP-1 contains three CUB repeats and one EGF-like repeat. The length of the signal peptide and propeptide at the $\mathrm{N}$ terminus is different among the members of the family.

kindling, and long-term potentiation (LTP) in rat hippocampus (Qian et al., 1993). Recently, we have found that treatment of Aplysia pleural-pedal ganglia with human TGF- $\beta 1$ produced longterm presynaptic facilitation of the sensorimotor connections

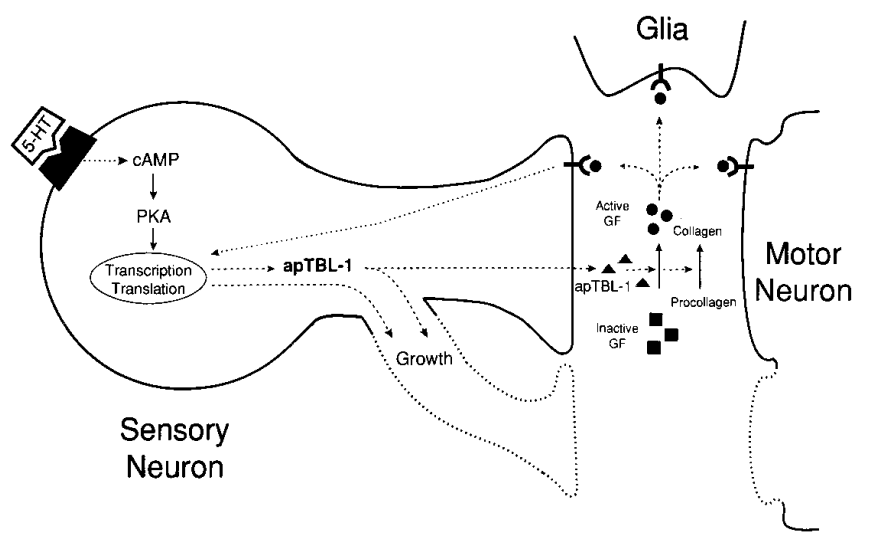

Figure 9. Model of possible roles of apTBL-1 in long-term presynaptic facilitation. A sensory neuron, motor neuron, and glial cell are represented schematically. The growth processes of sensory neurons and motor neurons are drawn with dotted lines. 5-HT increases the transcription of the apTBL-1 gene. apTBL-1 protein might remain in the cytoplasm by alternative translation and might play a role as a protease to modify the cytoskeleton structure in the growth process within the sensory neuron. apTBL-1 also might be secreted to modify the extracellular matrix (procollagen) or activate TGF- $\beta$-like growth factors. The activated growth factors could bind to Ser/Thr kinase receptors and trigger the signal transduction cascade, leading to the regulation of cell growth. The activated growth factors also might modify the motor neurons to complement the morphological changes in the sensory neurons, or they might activate glial cells to secrete extracellular matrix components that might then stabilize the morphological changes. Some of the same events elicited by the activation of TGF- $\beta$ also could be caused by modification of the extracellular matrix component collagen.
(Zhang et al., 1996). Another growth factor BDNF has also been reported to induce long-term facilitation in Aplysia (McKay and Carew, 1996).

Some of the possible roles of Aplysia tolloid/BMP-1-like proteins in the formation of memory are illustrated in Figure 9. Basal expression of apTBL-1 might be involved in processing and turnover of collagen (Kessler et al., 1996). Serotonin might increase the transcription of the apTBL-1 gene. apTBL-1 protein might remain in the cytoplasm by alternative translation and play a role to modify the cytoskeleton associated with the growth process. On the other hand, apTBL-1 might also be secreted and function as a protease. Extracellular proteases might be involved in synaptic plasticity by several potential functions: (1) proteolytic activation of growth factors (Kingsley, 1994), (2) matrix regulation (Matrisian, 1992; Kessler et al., 1996), and (3) ligand-receptor binding by EGF-like domains (Doherty et al., 1995). The ultimate targets of protease activity could be the sensory neurons, motor neurons, or glial cells (Fig. 9). The function of apTBL-1 could be to induce morphological or other changes that then would cause "long"term $(24 \mathrm{hr})$ or "very long"-term ( $>48 \mathrm{hr})$ synaptic facilitation. Because morphological changes appear rather quickly (soon after $1.5 \mathrm{hr}$ training or treatment periods), secreted apTBL-1 might not be a primary mediator of the early morphological changes. It is more likely that secreted apTBL- 1 is involved in maintaining the changes that initially are put into motion by 5-HT or behavioral training. Therefore, apTBL-1 could be part of a feedback control pathway that sustains an early memory. Such feedback factors have been proposed to play a role in differentiation (because it requires continuous active control) and in mechanisms for memory (Blau, 1992; Lisman, 1995). It has been hypothesized that similar mechanisms regulate development and synaptic plasticity associated with long-term memory (see, for example, Kandel and O’Dell, 1992; Marcus et al., 1994). 


\section{REFERENCES}

Alberini CM, Ghirardi M, Metz R, Kandel ER (1994) C/EBP is an immediate-early gene required for the consolidation of long-term facilitation in Aplysia. Cell 76:1-20.

Altschul SF, Gish W, Miller W, Myers EW, Lipman DJ (1990) Basic local alignment search tool. J Mol Biol 215:403-410.

Appella E, Weber IT, Blasi F (1988) Structure and function of epidermal growth factor-like regions in proteins. FEBS Lett 231:1-4.

Bailey CH and Chen M (1983) Morphological basis of long-term habituation and sensitization in Aplysia. Science 220:91-93.

Bailey CH, Chen M (1988) Long-term memory in Aplysia modulates the total number of varicosities of single identified sensory neurons. Proc Natl Acad Sci USA 85:2373-2377.

Bailey CH, Chen M, Keller F, Kandel ER (1992) Serotonin-mediated endocytosis of apCAM: An early step of learning-related synaptic growth in Aplysia. Science 256:645-649.

Bailey CH, Kandel ER (1993) Structural changes accompanying memory storage. Annu Rev Physiol 55:397-426.

Bartsch D, Ghirardi M, Skehel PA, Karl KA, Herder SP, Chen M, Bailey CH, Kandel ER (1995) Aplysia CREB2 represses long-term facilitation: relief of repression converts transient facilitation into long-term functional and structural change. Cell 83:979-992.

Barzilai A, Kennedy TE, Sweatt JD, Kandel ER (1989) 5-HT modulates protein synthesis and the expression of specific proteins during longterm facilitation in Aplysia sensory neurons. Neuron 2:1577-1586.

Bernier L, Castellucci VF, Kandel ER, Schwartz JH (1982) Facilitatory transmitter causes a selective and prolonged increase in adenosine $3^{\prime}, 5^{\prime}$-monophosphate in sensory neurons mediating the gill and siphon withdrawal reflex in Aplysia. J Neurosci 2:1682-1691.

Blau H (1992) Differentiation requires continuous active control. Annu Rev Biochem 61:1213-1230.

Bork P and Beckmann G (1993) The CUB domain. A widespread module in developmentally regulated proteins. J Mol Biol 231:539-545.

Bradford MM (1976) A rapid and sensitive method for the quantitation of microgram of protein utilizing the protein-dye bininding. Anal Biochem 72:248-254.

Byrne JH (1987) Cellular analysis of associative learning. Physiol Rev 67:329-439.

Byrne JH, Zwartjes R, Homayouni R, Critz SD, Eskin A (1993) Roles of second messenger pathways in neuronal plasticity and in learning and memory. Advances in Second Messenger and Phosphoprotein Research 27:47-108.

Castellucci VF, Kandel ER (1976) Presynaptic facilitation as a mechanism for behavioral sensitization in Aplysia. Science 194:1176-1178.

Castellucci VF, Blumenfeld H, Goelet P, Kandel ER (1989) Inhibitor of protein synthesis blocks long-term behavioral sensitization in the isolated gill-withdrawal reflex of Aplysia. J Neurobiol 20:1-9.

Clark GA, Kandel ER (1993) Induction of long-term facilitation in Aplysia sensory neurons by local application of serotonin to remote synapses. Proc Natl Acad Sci USA 90:11411-11415.

Dash PK, Hochner B, Kandel ER (1990) Injection of the cAMPresponsive element into the nucleus of Aplysia sensory neurons blocks long-term facilitation. Nature 345:718-721.

Doherty P, Williams E, Walsh FS (1995) A soluble chimeric form of the L1 glycoprotein stimulates neurite outgrowth. Neuron 14:57-66.

Dumermuth E, Sterchi EE, Jiang W, Wolz RL, Bond JS, Flannery AV, Beynon RJ (1991) The astacin family of metalloendopeptidases. J Biol Chem 266:21381-21385.

Emptage NJ and Carew TJ (1993) Long-term synaptic facilitation in the absence of short-term facilitation in Aplysia neurons. Science 262:253-256.

Ferguson EL, Anderson KV (1992) Localized enhancement and repression of the activity of the TGF- $\beta$ family member, decapentaplegic, is necessary for dorsal-ventral pattern formation in the Drosophila embryo. Development 114:583-597.

Frost WN, Castellucci VF, Hawkins RD, Kandel ER (1985) Monosynaptic connections made by the sensory neurons of the gill- and siphonwithdrawal reflex in Aplysia participate in the storage of long-term memory for sensitization. Proc Natl Acad Sci USA 82:8266-8269.

Fukagawa M, Suzuki N, Hogan BL, Jones CM (1994) Embryonic expression of mouse bone morphogenetic protein-1 (BMP-1) which is related to the Drosophila dorsoventral gene tolloid and encodes a putative astacin metalloendopeptidase. Dev Biol 163:175-183.

Girault J-A, Gorelick FS, Greengard P (1989) Improving the quality of immunoblots by chromatography of polyclonal antisera on keratin affinity columns. Anal Biochem 182:193-196.

Glanzman DL, Mackey SL, Hawkins RD, Dyke AM, Lloyd PE, Kandel ER (1989) Depletion of serotonin in the nervous system of Aplysia reduces the behavioral enhancement of gill withdrawal as well as the heterosynaptic facilitation produced by tail shock. J Neurosci 9:4200-4213.

Hu Y, Barzilai A, Chen M, Bailey CH, Kandel ER (1993) 5-HT and cAMP induce the formation of coated pits and vesicles and increase the expression of clathrin in sensory neurons of Aplysia. Neuron 10:921-929.

Hwang S-PL, Partin JS, Lennarz WJ (1994) Characterization of a homolog of human bone morphogenetic protein 1 in the embryo of the sea urchin, Strongylocentrotus purpuratus. Development 120:559-568.

Jonas EA, Knox RJ, Kaczmarrek LK, Schwartz JH, Solomon DH (1996) Insulin receptor in Aplysia neurons: Characterization, molecular cloning, and modulation of ion currents. J Neurosci. 16:1645-1658.

Kaang BK, Kandel ER, Grant SGN (1993) Activation of cAMP -responsive genes by stimuli that produce long-term facilitation in Aplysia sensory neurons. Neuron 10:427-435.

Kandel ER, O'Dell TJ (1992) Are adult learning mechanisms also used for development? Science 258: 243-245.

Kandel ER and Schwartz JH (1982) Molecular biology of learning: modulation of transmitter release. Science 218:433-443.

Kennedy TE, Kuhl D, Barzilai A, Sweatt JD, Kandel ER (1992) Longterm sensitization training in Aplysia leads to an increase in calreticulin, a major presynaptic calcium-binding protein. Neuron 9:1013-1024.

Kessler E, Takahara K, Biniaminov L, Brusel M and Greenspan DS (1996) Bone morphogenetic protein-1: the type I procollagen C-proteinase. Science 271:360-362.

Kingsley DM (1994) The TGF- $\beta$ superfamily: new members, new receptors, and new genetic tests of function in different organisms. Genes and Develop 8:133-146.

Kozak M (1987) A analysis of 5'-noncoding sequences from 699 vertebrate messenger RNAs. Nucleic Acids Res 15:8125-8148.

Kuhl D, Kennedy TE, Barzilai A, Kandel ER (1992) Long-term sensitization training in Aplysia leads to an increase in the expression of BiP, the major protein chaperon of the ER. J Cell Biol 119:1069-1076.

Kühn K (1987) The classical collagens: Type I, II, III. In: Structure and function of collagen types. (Mayne, R and Burgeson, R E eds). pp1-42. Academic Press.

Laemmli UK (1970) Cleavage of structural proteins during the assembly of the head of bacteriophage T4. Nature 227:680-685.

Lee JJ, Costlow NA (1987) A molecular titration assay to measure transcript prevalence levels. Methods Enzymol 152:633-648.

Lee WL, Aguirre M, Cleary LJ Byrne JH (1995) Cellular correlates of long-term sensitization in Aplysia. Soc Neurosci Abstr 21:1680.

Liang P and Pardee AB (1992) Differential display of eukaryotic messenger RNA by means of the polymerase chain reaction. Science 257:967-971.

Liang P, Averboukh L, Pardee AB (1993) Distribution and cloning of eukaryotic mRNAs by means of differential display: refinements and optimization. Nucleic Acids Res. 21:3269-3275.

Lisman J (1995) What does the nucleus know about memories? J NIH Res 7:43-46.

Liu QR, Lopez-Corcuera B, Mandiyan S, Nelson H, Nelson N (1993) Molecular characterization of four pharmacologically distinct $\gamma$-aminobutyric acid transporters in mouse brain. J Biol Chem 268:2106-2112.

Maeno M, Xue Y, Wood TI, Ong RC and Kung H (1993) Cloning and expression of cDNA encoding Xenopus laevis bone morphogenetic protein-1 during early embryonic development. Gene 134:257-261.

March SC, Parikh I, Cuatrecasas P (1974) A simplified method for cyanogen bromide activation of agarose for affinity chromatography. Anal Biochem 60:149-152.

Massague J (1990) The transforming growth factor- $\beta$ family. Annu Rev Cell Biol 6:597-641.

Mayford M, Barzilai A, Keller F, Schacher S, Kandel ER (1992) Modulation of an NCAM-related adhesion molecule with long-term synaptic plasticity in Aplysia. Science 256:638-644.

Marcus EA, Emptage NJ, Marois R, Carew TJ (1994) A comparison of the mechanistic relationships between development and learning in Aplysia. Prog Brain Res 100:179-188.

Matrisian LM (1992) The matrix-degrading metalloproteinases. BioEssays 14:455-463.

McKay SE, Carew TJ (1996) Growth factor-induced long-term synaptic 
facilitation in tail sensorimotor synapses of Aplysia. Soc. Nerosci. Abstr. 22:695.

Montarolo PG, Goelet P, Castellucci VF, Morgan J, Kandel ER, Schacher S (1986) A critical period of macromolecular synthesis in long-term heterosynaptic facilitation in Aplysia. Science 234:1249-1254.

Nguyen T, Jamal J, Shimell MJ, Arora K, O'Connor MB (1994) Characterization of tolloid-related-1: A BMP-1-like product that is required during larval and pupal stages of Drosophila development. Develop Biol 166:569-586.

Noel F, Nunez-Regueiro M, Cook R, Byrne JH, Eskin A (1993) Longterm changes in synthesis of intermediate filament protein, actin and other proteins in pleural sensory neurons of Aplysia produced by an in vitro analogue of sensitization training. Mol Brain Res 19:203-210.

Peter N, Aronoff B, Wu F, Schacher S (1994) Decrease in growth coneneurite fasciculation by sensory or motor cells in vitro accompanies downregulation of Aplysia cell adhesion molecules by neurotransmitters. J Neurosci 14:1413-1421.

Qian Z, Gilbert ME, Colicos MA, Kandel ER, Kuhl D (1993) Tissueplasminogen activator is induced as an immediate-early gene during seizure, kindling, long-term potentiation. Nature 361:453-457.

Rees DJG, Jones IM, Handford PA, Walter SJ, Esnouf MP, Smith KJ, Brownlee GG (1988) The role of $\beta$-hydroxyaspartate and adjacent carboxylate residues in the first EGF-domain of human factor IX. EMBO J 7:2053-2061.

Schacher S, Castellucci VF, Kandel ER (1988) cAMP evokes long-term facilitation in Aplysia sensory neurons that requires new protein synthesis. Science 240:1667-1669.

Scholz KP, Byrne JH (1987) Long-term sensitization in Aplysia: biophysical correlates in tail sensory neurons. Science 235:685-687.

Scholz KP, Byrne JH (1988) Intracellular injection of cAMP induces a long-term reduction of neuronal $\mathrm{K}^{+}$currents. Science 240:1664-1666.

Shaw $G$ and Kamen R (1986) A conserved AU sequence from the $3^{\prime}$ untranslated region of GM-CSF mRNA mediates selective mRNA degradation. Cell 46:659-667.
Shimell MJ, Ferguson EL, Childs SR, O'Connor MB (1991) The Drosophila dorsal-ventral patterning gene tolloid is related to human bone morphogenetic protein 1. Cell 67:469-481.

Takahara K, Lyons GE, Greenspan DS (1994) Bone morphogenetic protein-1 and a mammalian tolloid homologue (mTld) are encoded by alteratively spliced transcripts which are differentially expressed in some tissues. J Biol Chem 269:32527-32578.

Thomsen GH, Melton DA (1993) Processed Vg1 protein is an axial mesoderm inducer in Xenopus. Cell 74:433-441.

Trudeau L-E, Castullucci VF (1995) Postsynaptic modifications in longterm facilitation in Aplysia: Upregulation of excitatory amino acid receptors. J Neurosci 15:1275-1284.

von Heijne G (1984) How signal sequences maintain cleavage specificity. J Mol Biol 173:243-251.

Walters ET, Byrne JH, Carew TJ, Kandel E (1983) Mechanoafferent neurons innervating tail of Aplysia. II. Modulation by sensitizing stimulation. J Neurophysiol 50:1543-1559.

Walters ET and Ambron RT (1995) Long-term alterations induced by injury and by 5-HT in Aplysia sensory neurons: convergent pathways and common signals? Trends Neurosci 18:137-142.

Wozney JM, Rosen V, Celeste AJ, Mitsock LM, Whitters MJ, Kriz RW, Hewick RM, Wang EA (1988) Novel regulators of bone formation: molecular clones and activities. Science 242:1528-1534.

Zhang F, Endo S, Cleary LJ, Eskin A, Byrne JH (1996) Transforming growth factor $\beta$ (TGF- $\beta$ ) may be involved in long-term synaptic facilitation in Aplysia. Soc Neurosci Abstr 18:1956.

Zhang ZS, Fang B, Marshak DW, Byrne JH, Cleary LJ (1991) Serotonergic varicosities make synaptic contact with pleural sensory neurons of Aplysia. J Comp Neurol 311:259-270.

Zwartjes RE, Noel F, Byrne JH, Eskin A (1991) Calmodulin synthesis and mRNA level are regulated in Aplysia neurons by treatments producing long-term facilitation. Soc Neurosci Abstr 17:1590. 